sioning is low and their period of parental care is the longest of any bird ${ }^{2}$. Their low reproductive rate and high life expectancy even among long-lived birds ${ }^{10}$ and, combined with their unusual morphology and foraging strategy, are examples of extreme adaptations to poorly provisioned tropical waters.

Henri Weimerskirch ${ }^{\star}$, Olivier Chastel*, Christophe Barbraud ${ }^{\star}$, Olivier Tostain $\dagger \neq$

${ }^{\star}$ Centre d'Etudes Biologiques de Chizé, UPR 1934

79360 Villiers en Bois, France

e-mail: henriw@cebc.cnrs.fr

$\dagger$ Association Arataï, 1 lotissement des Nénuphars, 97357 Rémire-Montjoly, Guyane, France

$\ddagger D I R E N, 17$ place des Palmistes, (more than 30 years) make them exceptional Centre National de la Recherche Scientifique,

97328 Cayenne Cedex, Guyane, France

1. Diamond, A. W. Condor 75, 200-209 (1973).

2. Nelson, B. N. Living Birds 14, 113-155 (1976).

3. Pennycuick, C. J. J. Exp. Biol. 102, 307-325 (1983).

4. Orta, J. in Handbook of the Birds of the World Vol. 1 (eds del Hoyo, J., Elliott, A. \& Sargatal, J.) 362-376 (Lynx, Barcelona, 1992).

5. Alerstam, T. Bird Migration (Cambridge Univ. Press, Cambridge, 1990).

6. Augstein, E. Meteorology over the Tropical Oceans (ed. Shaw, D. B.) (R. Meteorol. Soc., Bracknell, 1980).

7. Lack, D. Swifts in a Tower (Methuen, London, 1956).

8. Gould, P. J. in Pelagic Studies of Seabirds in the Central and Eastern Pacific Ocean (ed. King, W. B.) 6-52 (Smithsonian Inst., Washington, 1974).

9. Balance, L. T. \& Pitman, R. L. Proc. 22nd Int. Ornithol. Congr. (eds Adams, N. J. \& Slotow, R. H.) 2057-2071 (BirdLife S. Afr., Johannesburg, 1999).

10. Weimerskirch, H. in Biology of Marine Birds (eds Schreiber, E. A. \& Burger, J.) 115-135 (CRC, Boca Raton, Florida, 2001).

Competing financial interests: declared none.

\section{Crab-spiders manipulate flower signals}

\section{Pollinator attraction}

ome European species of crab-spider match the colour of the flower on which they lie in wait to ambush insect pollinators, a tactic that is presumed to camouflage them from their intended prey and from predators ${ }^{1,2}$. Here we show that the coloration of an Australian species of crabspider, Thomisus spectabilis, which is cryptic on the white daisy Chrysanthemum frutescens to the human eye, is highly conspicuous to ultraviolet-sensitive insect prey — but that, instead of repelling foraging honeybees (Apis mellifera) as might be expected, the contrast of the spider against the petals makes the flowers more attractive. The spider is apparently exploiting the bee's pre-existing preference for flowers with colour patterning.

Visual signals communicated at ultraviolet wavelengths, which are invisible to humans and are therefore more difficult to analyse ${ }^{3,4}$, may be used by ambush predators to manipulate their prey's behaviour and increase capture success. We have

investigated how $T$. spectabilis interferes with floral signals, and the effect of its visibility on the attractiveness of the flower to pollinating insects.

Under natural light conditions, we presented honeybees with pairs of randomly selected white daisies, one of which carried an anaesthetized spider, and recorded which of the two flowers the bee visited first. We then repeated the experiment using a plastic foil covering on each flower and spider; the cover blocked olfactory cues but was transparent to light of wavelengths greater than $300 \mathrm{~nm}$.

Compared with empty flowers, the presence of white crab-spiders on the petals of daisies evidently attracted honeybees more, in both the presence and absence of olfactory cues (Fig. 1a). This indicates that the bees must have been guided by visual signals alone, and that the visual signal generated by the spider renders the flower more inviting to bees.

To identify this signal, we measured the spectral reflectance from 300 to $700 \mathrm{~nm}$ of the flower petals and of the spiders' abdomens. We calculated the colour contrast ${ }^{5}$ of the spiders against the flower petals and
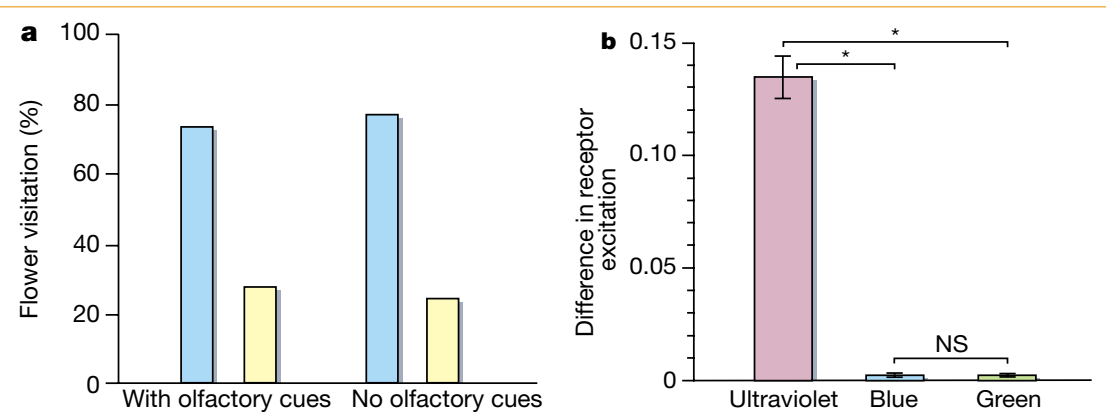

Figure 1 The effect of the presence of the crab-spider Thomisus spectabilis on the white daisy (Chrysanthemum frutescens) on flower visitation by honeybees (Apis mellifera). a, Proportion of bees that visit vacant daisies (yellow bars) and daisies occupied by spiders (blue bars) in the presence (binomial test, $n=33, P=0.0045)$ and absence $(n=25, P=0.0053)$ of olfactory cues. All spiders, flowers and bees were used only once. $\mathbf{b}$, Difference in honeybee colour-receptor excitation values (mean \pm s.e.; for methods, see ref. 2) between spiders' abdomens and daisy petals at different wavelengths (ultraviolet receptors, $\lambda_{\max }=345 \mathrm{~nm}$; blue receptors, $\lambda_{\max }=440 \mathrm{~nm}$; green receptors, $\lambda_{\max }=535 \mathrm{~nm}$; ref. 7). Tukey test, asterisk denotes $P<0.001$; NS, not significant. computed the euclidean distances in the colour space of hymenopterans ${ }^{2}$. We found that, compared with the flowers, white spiders reflect a considerable amount of ultraviolet light.

There was also a pronounced difference in the honeybee receptor-excitation values generated by spiders and flowers at ultraviolet wavelengths (Tukey-tests, $P<0.001$ and $P<0.001$, respectively), but not in the blue and green regions of the spectrum (ANOVA, $F_{2,74}=136.8, P<0.001$; Fig. $1 b$ ), where receptor excitation is comparable for both (Tukey test, $P=0.901$ ). Consequently, instead of being cryptic, as they are to humans, the spiders produce a strong colour contrast that is detectable by their hymenopteran prey (mean euclidean distance in colour space \pm s.e., $0.14 \pm 0.01$; $n=25)$. The values for colour contrast are well above the detection threshold of 0.05 (ref. 2; one-sample $t$-test, $t_{24}=7.6, P<0.001$ ).

We conclude that $T$. spectabilis uses quite the opposite signalling strategy to that known to be used by other crab-spiders ${ }^{1,2}$. T. spectabilis is difficult to perceive from far away, when bees use only their green-receptor signal to detect objects ${ }^{6}$, but is highly conspicuous in the insect visual spectrum when seen at close quarters. Because ultraviolet-reflecting white flowers are extremely rare in nature ${ }^{5}$, the spider will contrast strongly with almost any natural flower.

T. spectabilis will also be just as conspicuous to other flower visitors, as all known pollinating insects, including stingless bees ${ }^{7}$ (which are the spider's most likely Australian native prey), perceive ultraviolet light. We propose that the presence of spiders on flower petals creates a colour pattern that is particularly effective because bees have a pre-existing bias towards it an idea that is consistent with empirical data showing that bees innately prefer flowers with strongly contrasting markings ${ }^{8}$.

Astrid M. Heiling ${ }^{\star} \dagger$, Marie E. Herberstein $\dagger$, Lars Chittka $\ddagger$

${ }^{\star}$ Institute of Zoology, University of Vienna, 1090 Vienna, Austria

e-mail: astrid.heiling@univie.ac.at

$\dagger$ Department of Biological Sciences, Macquarie University, North Ryde, New South Wales 2109, Australia

$¥$ School of Biological Sciences, Queen Mary College, University of London, London E1 4NS, UK

1. Chittka, L. Entomol. Genet. 25, 181-187 (2001).

2. Thery, M. \& Casas, J. Nature 415, 133 (2002).

3. Endler, J. A. Biol. J. Linn. Soc. 41, 315-352 (1990).

4. Bennett, A. T. D., Cuthill, I. C., Partridge, J. C. \& Lunau, K. Proc. Natl Acad. Sci. USA 94, 8618-8621 (1997).

5. Chittka, L., Shmida, A., Troje, N. \& Menzel, R. Vision Res. 34, 1489-1508 (1994).

6. Giurfa, M., Vorobyev, M., Brandt, R., Posner, B. \& Menzel, R. J. Comp. Physiol. A 180, 235-243 (1997).

7. Briscoe, A. D. \& Chittka, L. Annu. Rev. Entomol. 46, 471-510 (2001).

8. Lunau, K., Wacht, S. \& Chittka, L. J. Comp. Physiol. A 178, 477-489 (1996).

Competing financial interests: declared none 